\title{
Erratum to: Defective Leukocyte Adhesion and Chemotaxis Contributes to Combined Immunodeficiency in Humans with Autosomal Recessive MST1 Deficiency
}

\author{
Tarana Singh Dang ${ }^{1} \cdot$ Joseph D. P. Willet ${ }^{1} \cdot$ Helen R. Griffin ${ }^{2} \cdot$ Neil V. Morgan $^{3}$ • \\ Graeme O'Boyle $^{1}$ - Peter D. Arkwright ${ }^{4} \cdot$ Stephen M. Hughes ${ }^{4} \cdot$ Mario Abinun ${ }^{1,5}$. \\ Louise J. Tee ${ }^{3}$ - Dawn Barge ${ }^{6} \cdot$ Karin R. Engelhardt $^{1} \cdot$ Michael Jackson $^{5}$. \\ Andrew J. Cant ${ }^{1,5}$ • Eamonn R. Maher ${ }^{3,7}$ - Mauro Santibanez Koref ${ }^{2}$. \\ Louise N. Reynard $^{1} \cdot$ Simi Ali $^{1} \cdot$ Sophie Hambleton ${ }^{1,5}$
}

Published online: 3 March 2016

(C) Springer Science+Business Media New York 2016

Erratum to: J Clin Immunol (2016)

DOI 10.1007/s10875-016-0232-2

The original version of this article unfortunately contained mistakes in Table 1 and author's contribution. The correct version is presented on the next page.

Tarana Singh Dang and Joseph D. P. Willet contributed equally to this work.

The online version of the original article can be found at http://dx.doi.org/ 10.1007/s10875-016-0232-2.

Sophie Hambleton

sophie.hambleton@newcastle.ac.uk

Institute for Cellular Medicine, Newcastle University, Newcastle upon Tyne NE2 4HH, UK

2 Institute of Genetic Medicine, Newcastle University, Newcastle upon Tyne, UK

3 School of Clinical and Experimental Medicine, University of Birmingham, Birmingham, UK

4 Department of Paediatric Allergy \& Immunology, Royal Manchester Children's Hospital, University of Manchester, Manchester, UK

5 Great North Children's Hospital, Newcastle upon Tyne Hospitals NHS Foundation Trust, Newcastle upon Tyne, UK

6 Blood Sciences Flow Cytometry Laboratory, Newcastle upon Tyne Hospitals NHS Foundation Trust, Newcastle upon Tyne, UK

7 Department of Medical Genetics, University of Cambridge, Cambridge, UK 
Table 1 Clinical features and laboratory values for patients, demonstrating profound CD4lymphopenia and reduced lymphoproliferative responses

\begin{tabular}{|c|c|c|c|c|}
\hline Feature $^{\mathrm{a}}$ & $\mathrm{P} 1$ & $\mathrm{P} 2$ & P3 & Normal range $\mathrm{c}^{\mathrm{c}}$ \\
\hline \multicolumn{5}{|l|}{ Clinical features } \\
\hline Eczema \& skin infections & + & + & - & \\
\hline Recurrent sinopulmonary infection & + & + & - & \\
\hline Oral candidiasis & - & + & - & \\
\hline Cryptosporidiosis & + & + & + & \\
\hline \multicolumn{5}{|l|}{ Viral infections: } \\
\hline Molluscum contagiosum & + & + & + & \\
\hline Recurrent VZV & - & - & + & \\
\hline Severe $1^{\circ} \mathrm{HSV}$ & + & + & - & \\
\hline Chronic EBV viremia & + & + & + & \\
\hline EBV LPD & + & + & - & \\
\hline \multicolumn{5}{|c|}{ Flow cytometric immunophenotyping (absolute cell counts per $\mu 1$ except where $\%$ indicated) } \\
\hline $\mathrm{CD}^{+} \mathrm{T}$ cells & 815 & 850 & 921 & $1400-8000$ \\
\hline $\mathrm{CD}^{+}{ }^{\mathrm{T}}$ cells & 200 & 268 & 368 & $900-5500$ \\
\hline${ }^{\mathrm{b}}$ naive $\mathrm{CD} 4^{+} \mathrm{T}$ cells & 0 & 17 & 18 & \\
\hline $\mathrm{CD}^{+} \mathrm{T}$ cells & 512 & 592 & 523 & $400-2300$ \\
\hline${ }^{\mathrm{b}}$ naïve $\mathrm{CD} 8^{+} \mathrm{T}$ cells & 16 & 17 & 28 & \\
\hline TCR- $\gamma \delta^{+}(\%$ of T cells $)$ & 28 & 7 & 15 & \\
\hline HLA-DR $^{+}(\%$ of T cells $)$ & 84 & 77 & 62 & \\
\hline $\mathrm{CD} 16^{+} / \mathrm{CD} 6^{+} \mathrm{NK}$ cells & 192 & 147 & 298 & $100-1400$ \\
\hline $\mathrm{CD} 19^{+} \mathrm{B}$ cells & 439 & 897 & 1355 & $600-3100$ \\
\hline $\mathrm{CD} 27^{+} \operatorname{IgD}^{-}(\%$ of B cells $)$ & 2 & 3 & 5 & \\
\hline \multicolumn{5}{|l|}{ Lymphocyte proliferation assay } \\
\hline PHA patient (cpm) & 11,326 & 34,343 & 67,254 & \\
\hline PHA control (cpm) & 148,110 & 122,215 & 101,164 & \\
\hline SI patient & 82 & 29 & 94 & \\
\hline SI control & 445 & 407 & 349 & \\
\hline \multicolumn{5}{|l|}{ Immunoglobulins } \\
\hline $\operatorname{Ig} G$ & 18.3 & 28.8 & 17.8 & $3.0-13.3 \mathrm{~g} / \mathrm{L}$ \\
\hline $\operatorname{Ig} A$ & 2.2 & 4.47 & 0.7 & $0.3-1.29 \mathrm{~g} / \mathrm{L}$ \\
\hline $\operatorname{Ig} M$ & 0.6 & 1.13 & 0.9 & $0.43-1.9 \mathrm{~g} / \mathrm{L}$ \\
\hline Pneumococcal $a b$ & $<3$ & 17 & 88 & 20-200 mg/L \\
\hline Tetanus $a b$ & 0.88 & 1.55 & 0.49 & $0.1-10 \mathrm{IU} / \mathrm{ml}$ \\
\hline Hemophilus B ab & NT & $>9.0$ & NT & $1.0-20 \mathrm{mg} / \mathrm{L}$ \\
\hline
\end{tabular}

$V Z V$ Varicella zoster virus, $H S V$ Herpes simplex virus, $E B V$ Epstein Barr Virus, $L P D$ lymphoproliferative disease, $P H A$ phytohemagglutinin, $c p m$ counts per minute, SI stimulation index, $a b$ specific antibody, NT not tested

${ }^{\text {a }}$ Laboratory evaluation was performed at 5.5 years $(\mathrm{P} 1)$, 3.4 years $(\mathrm{P} 2), 1.7$ years $(\mathrm{P} 3)$

${ }^{\mathrm{b}}$ Naïve T cells were defined as CD3 + CD27 + CD45RA+ and as either CD4+ or CD4-

${ }^{\mathrm{c}}$ Normal ranges are age matched to $\mathrm{P} 3$ 